\title{
Effect of an organotitanate coupling agent on properties of calcium carbonate filled low-density polyethylene and natural rubber composites
}

\author{
W.D.M. Sampath ${ }^{1 *}$, S.M. Egodage ${ }^{2}$ and D.G. Edirisinghe ${ }^{1}$ \\ ${ }^{I}$ Rubber Technology and Development Department, Rubber Research Institute of Sri Lanka, Dartonfield, Agalawatte. \\ ${ }^{2}$ Department of Chemical and Process Engineering, Faculty of Engineering, University of Moratuwa, Katubedda, Moratuwa.
}

Submitted: 29 November 2017; Revised: 14 June 2018; Accepted: 17 August 2018

\begin{abstract}
Poor filler dispersion in a polymer matrix results in non-uniformity of the composite and hence changes its properties. This non-uniformity could be overcome by incorporating a suitable adhesion promoter and/or a coupling agent. Although titanate coupling agents are used in plastics, the use of a titanate coupling agent (CA) in rubberthermoplastic blends has not been studied in detail. Therefore, this study was aimed at incorporating a CA to natural rubber (NR) and low-density polyethylene (LDPE) blend through calcium carbonate $\left(\mathrm{CaCO}_{3}\right)$ filler and thereby investigating the effect of CA loading on properties of the composites. In this study, a series of 70/30 NR/LDPE composites was formulated by varying the CA loading from 0 to $1.5 \mathrm{pphp}$ (parts per hundred parts of polymer). $\mathrm{CaCO}_{3}$ loading was kept constant at $20 \mathrm{pphp}$. Brabender plasticorder was used to prepare composites at a temperature of $150{ }^{\circ} \mathrm{C}$, and a rotor speed of $60 \mathrm{rpm}$. Physico-mechanical properties were evaluated according to ISO standards. Degree of swelling and gel content in p-xylene, water absorption, morphology, ageing, thermal and dynamic properties of the composites were investigated. Tensile strength, elongation at break and tear strength of the composites increased with the addition of CA and showed the best properties at a CA loading of $0.7 \mathrm{pphp}$. Hardness increased with the addition of CA, however, it decreased with the increase in CA loading. The highest gel content, retention of tensile properties and water resistance were also shown at 0.7 pphp loading. In overall, the composite at CA loading of $0.7 \mathrm{pphp}$ showed better compatibility and the best properties.
\end{abstract}

Keywords: Calcium carbonate, low density polyethylene, natural rubber, physico-mechanical properties, titanate coupling agent.

\section{INTRODUCTION}

Low-density polyethylene (LDPE) is a highly branched long-chain thermoplastic and has a density between 0.915 to $0.925 \mathrm{~g} / \mathrm{cm}^{3}$ and molecular weight up to $4 \times 10^{6}$ (Rubin, 1990). Its relatively low melting point and broad melting range within $106-120^{\circ} \mathrm{C}$ result in easy process applications. Low glass transition temperature of approximately $-120{ }^{\circ} \mathrm{C}$, and the degree of crystallinity of 50-60\%, account for its softness and flexible nature (Seymour \& Carraher, 1984).

LDPE has combined properties such as high impact strength, toughness, and ductility to make it a choice for packaging films, which is one of its largest applications (Mahapram \& Poompradub, 2011). Films range from shrink film, thin film for automotive packaging, heavy sacking, and multilayer films (both laminated and coextruded) where LDPE acts as a seal layer or a water vapour barrier (Baker \& Mead, 2000).

Natural rubber (NR) has been extensively studied due to its wide usage in tyre production. Thermoplastics are commonly blended with NR to facilitate its processability by reducing melt viscosity and to improve its performances (Hernández-Sánchez et al., 1999). NR-thermoplastic blends are prepared by blending NR particularly with polypropylene (PP) and polyethylene $(\mathrm{PE})$ in various proportions. As the ratio varies, materials

*Corresponding author (wikcramage@yahoo.com; iD https://orcid.org/0000-0002-6481-7189) 
with a wide range of properties are obtained. Soft grades of NR-thermoplastic blends containing up to $30 \%$ of thermoplastic exhibit rubbery properties (Sampath et al., 2015). Blends having thermoplastics above $30 \%$ show properties of a plastic material as the continuous phase is changed from NR to thermoplastic. NR-thermoplastic blends are considerably improved if the NR phase is partially cross-linked during mixing through dynamic vulcanisation (Maziad et al., 2009). The blends are more resistant to heat ageing than NR vulcanisates. Ozone resistance of the blends is also high (Maziad et al., 2009). The soft grade blends can replace vulcanised rubber and flexible plastic for applications in footwear, sports goods, seals and mountings and a wide range of molded and extruded goods. Further, NR/LDPE blends have been developed for light weight good quality microcellular soles (Srilathakutty et al., 1999), while hard grades of NR/LDPE or high-density polyethylene blends are used for roofing applications (Wickramaarachchi et al., 2016).

Two series of NR/LDPE and NR/polystyrene (PS) blends were prepared in a previous study at blend ratios; 100:0, 85:15, 70:30 and 55:45. The 70:30 NR/LDPE blend showed excellent chemical resistance and it was considered as the best blend ratio owing to its excellent tensile properties (Mohammed \& Qusay, 2014). Further, the blend of 70:30 NR/LDPE prepared with N-Isopropyl$\mathrm{N}$-phenyl-1,4-phenylenediamine (IPPD) indicated good thermal stability due to its good ageing properties (Bhowmick \& White, 2002). Furthermore, 70:30 NR/PE blends have been developed as possible replacements for the conventional NR/HSR (high styrene resin) based soles (Srilathakutty et al., 1999). The above results from literature indicate that the 70:30 NR/LDPE thermoplastic elastomer blend has remarkable properties and hence the same blend ratio was selected for this study.

Fillers are incorporated into both rubbers and thermoplastics to reduce the cost by increasing the volume, to reinforce the polymer and thereby to improve the performance of the final product. Calcium carbonate $\left(\mathrm{CaCO}_{3}\right)$, silica, talc and alumina hydrates are the commonly used non-black particulate fillers or mineral fillers in thermoplastics and rubbers. Dispersion of inorganics in polymers and adhesion of a polymer to an inorganic filler are difficult since many thermoplastics and rubbers such as olefin-based polymers are non-polar. Hence, $\mathrm{CaCO}_{3}$ does not show property enhancement when incorporated either into rubbers or to thermoplastics. $\mathrm{CaCO}_{3}$ is a natural product from sedimentary rocks and is separated into chalk, limestone and marble. In some cases, $\mathrm{CaCO}_{3}$ is treated to improve bonding with thermoplastics (Bosshard \& Schlumpt, 1987). $\mathrm{CaCO}_{3}$ can exist in a number of crystallographic modifications: calcite, aragonite and vaterite (Betingyte et al., 2012). Ground natural calcite is usually micron-sized with a broad size distribution and irregular in shape and is used as a filler extender. It is known that $\mathrm{CaCO}_{3}$ is the most widely used non-reinforcing filler in natural rubber composites. It is inexpensive and can be used at high loadings. According to literature, owing to the dissimilar nature of polyolefin and $\mathrm{CaCO}_{3}$, it is important to achieve a good dispersion of $\mathrm{CaCO}_{3}$ particles in polyolefin in order to obtain optimum performance of the composites. However, $\mathrm{CaCO}_{3}$ does not disperse easily in LDPE and it tends to agglomerate. Further, interactions of polyethylene with polar substances occur at a low level due to its crystallinity and polarity (Doufnoune et al., 2008). Hence, low loadings of LDPE such as $30 \mathrm{phpp}$ is blended with 70 phpp loading of NR. Nevertheless, properties of 70/30 NR/LDPE composites filled with $\mathrm{CaCO}_{3}$ are not at an acceptable level due to poor dispersion of $\mathrm{CaCO}_{3}$ in the LDPE phase as well as compatibility of the two polymer phases NR and LDPE. Conventional type titanate coupling agents could be used to increase the dispersion of $\mathrm{CaCO}_{3}$ in LDPE and to develop compatibility between NR and LDPE phases. Also, it was reported in literature that the dispersibility and compatibility of the inorganic phases of $\mathrm{HDPE} / \mathrm{CaCO}_{3}$ composite can be improved through surface treatment of the amorphous $\mathrm{CaCO}_{3}$ filler with stearic acid (Croitoru et al., 2017).

Titanate coupling agents are used to improve interfacial adhesion between hydrophobic polymers and hydrophilic fillers. Esters of titanium (or zirconium) couple or chemically bridge two dissimilar species such as inorganic filler/organic particulate filler/fibre and an organic polymer through proton coordination (Monte \& Sugerman, 1987). Titanium derived coupling agents are unique in their reactions with protons at the inorganic filler and result in the formation of organic monomolecular layers on the inorganic surface. Titanate-treated inorganic fillers are hydrophobic, organophilic and organofunctional. When incorporated into polymer systems, they often promote adhesion, improve dispersion, improve impact strength and thus reduce embrittlement and prevent phase separations of inorganic fillers at high filler loadings (Monte \& Sugerman, 1987). The different ways that these coupling agents work in filled polymers can be explained by breaking down the various mechanisms of the titanate molecule into six distinct functions and basic structure (Kattas et al., 2000).

The compatibility of $\mathrm{CaCO}_{3}$ to LDPE is poor and hence the composites provide inferior properties (Pietrasanta et al., 1998). The composites prepared with polybutadiene rubber (PBR) and titanate coupling agent treated clay have shown increased magnitudes of modulus at $400 \%$ 
elongation, tensile strength and Young's modulus when compared to untreated clay composite (Alkadasi et al., 2004). Effects of treatment of titanate coupling agent on mechanical properties of chloroprene rubber and flyash composite have been reported. The treatment resulted in enhancement of mechanical properties of composites of the said rubber when compared with untreated flyash composites separately. The properties under consideration were tensile strength, modulus at $100 \%$ and $400 \%$, Young's modulus, hardness, etc. Tensile strength was improved by $1365 \%$. Modulus at $400 \%$ was found to improve by $1410 \%$, while Young's modulus was improved by $1216 \%$ (Alkadasi et al., 2006). Further, treatment of magnesium hydroxide with titanium (IV) oxide has affected magnitudes of elongation at break, tensile strength, elastic modulus and hardness (Nabil et al., 2016).

Conventional type titanate coupling agents have been found to be very effective in modifying physicomechanical properties and rheological behaviour by providing lubrication action to the LDPE/polypropylene (PP) composites at the same time (Monte, 2005). The coupling of titanate to the inorganic/organic filler in monolayers allows for elimination of air voids, enhanced hydrophobicity and a complete continuous phase for stress/strain transfer (Monte, 2005). Typically, titanate treated inorganic fillers show dispersability and bonding with the polymer matrix (Pocius, 2012). However, the effect of titanate coupling agents in enhancing inorganic filler dispersion in rubbers and in NR/LDPE blends has not been studied in detail. Therefore, the use of a titanate coupling agent in developing a $\mathrm{CaCO}_{3}$ filled NR/LDPE (70/30) composite was studied and the effect of titanate coupling agent loading on properties of the composite is presented in this paper.

\section{METHODOLOGY}

\section{Materials}

Commercially available LDPE, and a raw NR type, ribbed smoked sheet rubber (RSS-2), were used as the two polymers to prepare composites. LDPE having melt flow index, density, and crystalline melting temperature of $2.4 \mathrm{~g} / 10 \mathrm{~min} ., 0.923 \mathrm{gcm}^{-3}$ and $115{ }^{\circ} \mathrm{C}$, respectively, was supplied by Deluxe Plastics Ltd., Sri Lanka. RSS-2 having plasticity retention index of 64 was supplied by the Rubber Research Institute of Sri Lanka. $\mathrm{CaCO}_{3}$ having mean particle size of 2 micron and density of $2.71 \mathrm{gcm}^{-3}$ was used as the filler and was obtained from Lanka Minerals and Chemicals (Pvt.) Ltd., Sri Lanka.

Titanate coupling agent (CA), a kind of neoalkoxy organotitanate of trade name 'Lica 12' in pellet form from Kenrich Pertrochemical Incorporation was supplied by Pheonix Industries, Sri Lanka. Chemical name of the coupling agent titanium IV 2 is 2(bis 2-propenolatomethyl) butanolato, tris (dioctyl) phosphato-O. It was used as received without further purification.

\section{Preparation of 70/30 NR/LDPE composites}

A series of 70/30 NR/LDPE composites was formulated by varying the CA loading from 0.3 to $1.5 \mathrm{pphp}$. The NR/ LDPE composite without CA was taken as the control. The formulation of the composites is given in Table 1. In addition, a 70/30 NR/LDPE simple blend without $\mathrm{CaCO}_{3}$ and CA was prepared. The composites were prepared by melt mixing using a Brabender Plasticorder operated at a temperature of $150{ }^{\circ} \mathrm{C}$ and at a rotor speed of $60 \mathrm{rpm}$. Total mixing time was kept constant at 14 min. Mixing cycle used in the preparation of NR/LDPE composites is

Table 1: Formulation of the NR/LDPE composites

\begin{tabular}{|c|c|c|}
\hline Ingredient & Function & $\begin{array}{l}\text { Parts per hundred parts of polymer } \\
\text { (pphp) }\end{array}$ \\
\hline NR & Rubber & 70 \\
\hline LDPE & Thermoplastic & 30 \\
\hline $\mathrm{CaCO}_{3}$ & Filler & 20 \\
\hline Dicumyl peroxide (DCP) & Vulcanizing agent & 0.5 \\
\hline Sulphur & Vulcanizing agent & 0.5 \\
\hline Zinc oxide & Inorganic activator & 5.0 \\
\hline Stearic acid & Organic activator & 2.0 \\
\hline $\begin{array}{l}\text { N-tert-butyl-2-benzothiazyl } \\
\text { sulfonamide (TBBS) }\end{array}$ & Accelerator & 1.0 \\
\hline Vulcanox BKF & Antioxidant & 1.0 \\
\hline Titanate Lica 12 & Coupling agent & $0, \quad 0.3, \quad 0.5,0.7,0.9,1.2,1.5$ \\
\hline
\end{tabular}


given in Table 2. NR/LDPE composites were compressed in an electrically heated hydraulic press at $150{ }^{\circ} \mathrm{C}$ under a pressure $0.35 \mathrm{MPa}$ for $15 \mathrm{~min}$ to produce $2 \mathrm{~mm}$ thick sheets. Test specimens were cut from these sheets according to the standards.

Table 2: Mixing cycle of the NR/LDPE composites

\begin{tabular}{cl}
\hline Total time, min & Ingredient \\
\hline 0 & LDPE \\
4 & NR \\
6 & Zinc oxide + Stearic acid + Antioxidant \\
7 & $1 / 2 \mathrm{CaCO}_{3}$ \\
8 & $1 / 2 \mathrm{CaCO}_{3}$ \\
9 & $\mathrm{CA}$ \\
11 & TBBS \\
12 & Sulphur + DCP \\
14 & Dumping the compound \\
\hline
\end{tabular}

\section{Characterization of NR/LDPE composites}

\section{Physico-mechanical properties}

Tensile properties and tear strengths of NR/LDPE composites were determined using the Instron tensile testing machine according to BS ISO 37:2010 and BS ISO 34-1:2010, respectively. Dumbbell shaped tensile test specimens and angle shaped tear test specimens were used. Crosshead speed was maintained at $50 \mathrm{~mm} / \mathrm{min}$. Hardness of the composites was determined using Dead Load Digi Test hardness tester according to BS ISO 48:2010, while hardness of the gels after extraction with boiled p-xylene was determined using a Shore A hardness tester.

\section{Degree of swelling}

Degree of swelling was determined as per ISO 1817:2011 standards. Three test specimens having dimensions of $30 \mathrm{~mm} \times 1 \mathrm{~mm} \times 2 \mathrm{~mm}$ were immersed in $\mathrm{p}$-xylene for $72 \mathrm{~h}$ in closed-lid bottles. Excess solvent on the surface of the specimen was removed by wiping with a blotting paper. Initial and swollen weights were measured and the degree of swelling (Q) was calculated according to equation (1).

$\mathrm{Q}(\%)=\frac{\left(\mathrm{m}-\mathrm{m}_{0}\right)}{\mathrm{m}_{0}} \times 100$

where, $\mathrm{m}_{0}$ and $\mathrm{m}$ are the weights of the specimen before and after swelling, respectively. Weights were recorded using an electric balance of sensitivity $\pm 0.0001 \mathrm{~g}$.

\section{Gel content}

Test specimens having dimensions of $1 \mathrm{~cm} \times 3 \mathrm{~cm} \times 0.2 \mathrm{~cm}$ were placed in a specimen holder and immersed in boiled p-xylene for $16 \mathrm{~h}$. The specimens were oven dried at $70{ }^{\circ} \mathrm{C}$ until a constant weight was obtained. Weights were measured to the nearest $0.1 \mathrm{mg}$. Percentage gel content (Q') was calculated according to equation (2) (Bengtsson et al., 2005).

$$
\mathrm{Q}^{\prime(\%)}=\frac{\mathrm{m}}{\mathrm{M}} \times 100
$$

where, $\mathrm{M}$ is the initial weight of the specimen, and $\mathrm{m}$ is the weight of the oven dried gel.

\section{Ash content}

Test specimens were prepared according to ISO 1796. The specimens were heated at $550{ }^{\circ} \mathrm{C}$ and cooled to room temperature. The total ash content (\%) was calculated according to ISO 247 [(weight of the ash) / (weight of the original sample) $\times 100]$.

\section{Ageing properties}

Accelerated ageing of the composites was carried out at $70{ }^{\circ} \mathrm{C}$ for $72 \mathrm{~h}$ in an air circulating oven. Tensile properties were evaluated after ageing and percentage retention of these properties were calculated according to equation (3).

Retension of tensile strength (\%) =

$$
\frac{\text { Tensile strength after ageing }}{\text { Tensile strength before ageing }} \times 100
$$

\section{Water absorption}

Water absorption of the composites was obtained by immersion of test specimens having dimensions of $30 \mathrm{~mm}$ $\times 10 \mathrm{~mm} \times 2 \mathrm{~mm}$ for $72 \mathrm{~h}$ in water at room temperature. Increase in weight to the initial weight of the specimen as a percentage was reported as the water absorption.

\section{Thermal properties}

The thermal properties of the NR/LDPE composites were examined by differential scanning calorimetry (DSC) using NETZSCH-DSC 204 F1 calorimeter. 
Approximately $10 \mathrm{mg}$ of composites was placed in an aluminum pan with a cover and scanned under a nitrogen atmosphere from room temperature to $150{ }^{\circ} \mathrm{C}$. The melting temperature $\left(\mathrm{T}_{\mathrm{m}}\right)$ was determined as the peak temperature of the melting endotherm, and the enthalpy of fusion $\left(\delta \mathrm{H}_{m}\right)$ was determined as the area of the melting endotherm. The degree of crystallinity $\left(X_{C}\right)$ was calculated via the total enthalpy method, according to equation 4 .

$$
X_{c},(\%)=\frac{\delta H_{m}}{\delta H_{m}^{0}} \times 100
$$

where, $\delta H_{m}^{0}$ is the enthalpy of fusion for pure crystalline LDPE and was taken as $288 \mathrm{~kJ} \mathrm{~kg}^{-1}$ (Saci et al., 2016).

\section{Dynamic mechanical analysis (DMA)}

Dynamic mechanical properties of the NR/LDPE composites were determined using a dynamic mechanical analyser, DMA Q 800 TA (USA). The dual cantilever mode of deformation was used. Rectangular test specimens having dimensions $40 \mathrm{~mm} \times 12 \mathrm{~mm} \times$ $2 \mathrm{~mm}$ were heated over the temperature range $-130{ }^{\circ} \mathrm{C}$ to $100{ }^{\circ} \mathrm{C}$, at a rate of $2{ }^{\circ} \mathrm{C} \mathrm{min}^{-1}$. Liquid nitrogen was used as the cooling medium. Storage modulus ( $\left.\mathrm{E}^{\prime}\right)$, loss modulus (E") and tan $\delta$ of each composite were recorded in temperature sweep mode at $1.0 \mathrm{~Hz}$.

\section{Morphological analysis}

Surface morphology of tensile fracture surfaces of NR/LDPE composites was examined by scanning electron microscopy (SEM) using a ZEISS EVO LS 15 microscope. The specimens were cut and mounted on aluminum stubs. The specimens were sputter coated with a thin layer of gold to avoid electrostatic charging during examination.

\section{RESULTS AND DISCUSSION}

\section{Physico-mechanical properties of NR/LDPE composites}

Stress-strain curves are an extremely important graphical measure of a material's mechanical properties such as tensile strength, modulus and elongation at break and help in calculating Young's modulus and explaining material behaviour. Figure 1 shows the stress-strain behaviour of composites with and without CA. All composites exhibit rubbery behaviour confirming that rubber is in the continuous phase. Further, composites with $\mathrm{CA}$ at most of the loadings show higher stresses and strains compared to the control. The area under the stress-strain curve explains the elastic potential energy of polymeric materials. Therefore, it shows a greater value when the CA loading is at $0.5 \mathrm{pphp}$ and $0.7 \mathrm{pphp}$. This shows that the two composites provide high elastic energy and good toughness.

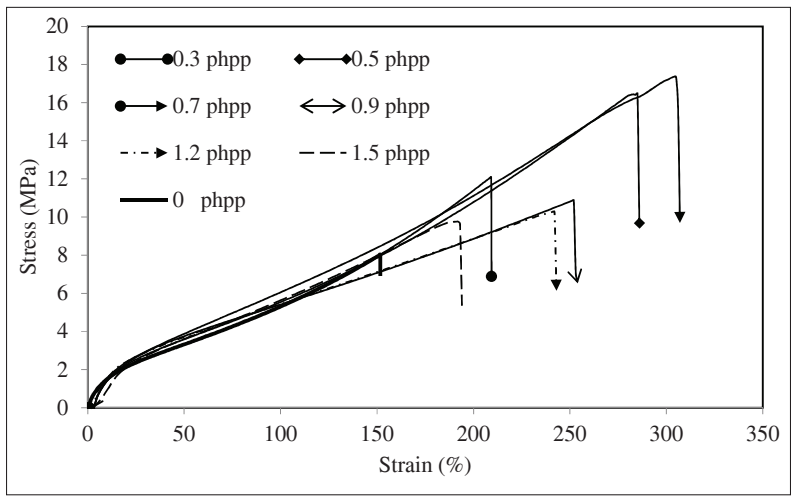

Figure 1: Stress-strain curves of NR/LDPE composites with CA at different loadings

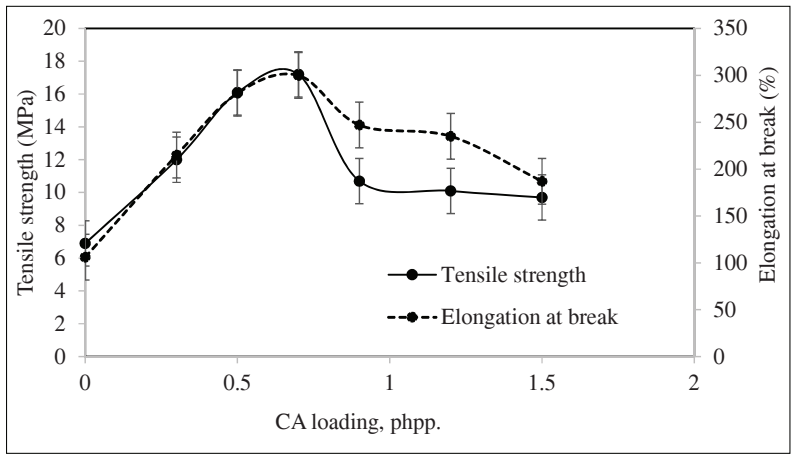

Figure 2: Variation of tensile strength and elongation at break of NR/LDPE composites with CA loading

Figure 2 shows that the tensile strength significantly increased with CA loading up to 0.7 pphp and then decreased. The best tensile strength is exhibited at a CA loading of 0.7 pphp and is associated with the higher degree of crystallinity of LDPE in the composites (Table 3), and may be with good interfacial adhesions between NR and LDPE. Poor interfacial adhesions develop poor stress transfer between the matrix and the dispersed phase (George et al., 1995), and will decrease tensile strengths at higher CA loadings. The excess CA, which is the amount greater than necessary to form a monolayer, would not result in a plastic network at the interface (Pocius, 1997) and therefore, it is suspected that it can form a weak boundary layer resulting in poor properties. 
Table 3: Thermal properties of NR/LDPE composites

\begin{tabular}{lccc}
\hline CA loading, pphp & $\mathrm{T}_{\mathrm{g}},{ }^{\circ} \mathrm{C}$ & $\mathrm{T}_{\mathrm{m},}{ }^{\circ} \mathrm{C}$ & $\mathrm{X}_{\mathrm{C}}, \%$ \\
\hline Control & -56.4 & 109.3 & 20.4 \\
0.3 & -62.1 & 109.8 & 35.5 \\
0.5 & -62.6 & 110.3 & 59.4 \\
0.7 & -62.6 & 110.2 & 59.8 \\
0.9 & -62.1 & 107.5 & 51.1 \\
1.2 & -62.3 & 107.8 & 52.8 \\
1.5 & -61.7 & 107.0 & 40.3 \\
\hline
\end{tabular}

$\mathrm{T}_{\mathrm{g}}$ : glass transition temperature; $\mathrm{T}_{\mathrm{m}}$ : melting temperature; $\mathrm{X}_{\mathrm{c}}$ : degree of crystallinity

Table 4: Ash content of NR/LDPE composites

\begin{tabular}{lc}
\hline CA loading (pphp) & Ash content (\%) \\
\hline Control & 21.5 \\
0.5 & 23.5 \\
0.7 & 30.2 \\
\hline
\end{tabular}

Furthermore, viscosity of the composites will decrease at higher CA loadings to decrease tensile strength. It was reported that the titanate treated inorganic fillers show good dispersability and bonding with plastics in composites (Monte et al., 2005), but at higher loadings of $\mathrm{CA}$, it reacted as a plasticiser by decreasing the viscosity of plastic composites. Elongation at break also increases with the addition of $\mathrm{CA}$, and further increases with loading up to $0.7 \mathrm{pphp}$. Elongation at break decreases thereafter with further addition of CA loading (Figure 2). According to Figure 2, 0.7 pphp will be the optimum CA loading to enhance the interfacial adhesions between LDPE and NR phases through $\mathrm{CaCO}_{3}$.

Hardness of NR/LDPE composites at different CA loadings are shown in Figure 3. Hardness of all composites measured is within the range $60-65$ IRHD. This confirms the presence of rubber in the continuous phase in all composites, and is in agreement with the stress-strain behaviour shown in Figure 1. Hardness of all composites with CA is greater than that of the control, and is associated with the formation of crosslinks between the two polymer phases. Hardness increases with the addition of CA loading at 0.3 pphp by $5 \%$, and decreases thereafter with increase in CA loading. This decrease may be due to the enhancement in plasticising effect of CA at higher loadings. Furthermore, the longer crosslinks developed through $\mathrm{CaCO}_{3}$ with increase of CA loading might have provided a softness to the composite.

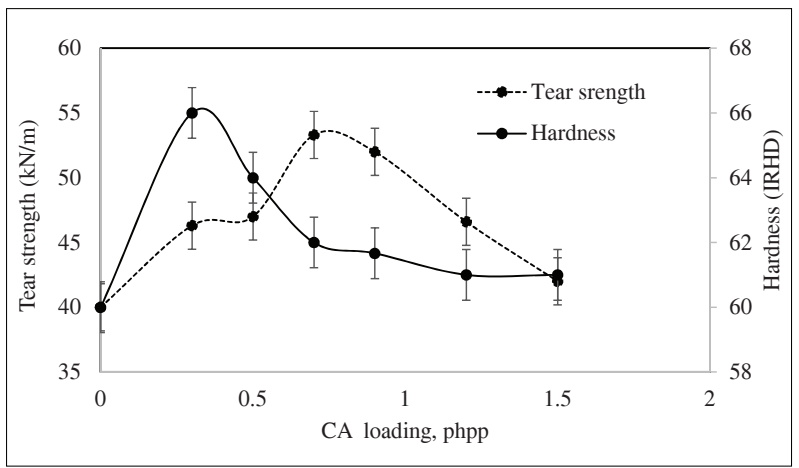

Figure 3: Variation of tear strength and hardness of NR/LDPE composites with CA loadings

Tear strength of a polymeric material depends mainly on the crack propagation property. Tear strengths of the composites show a variation from $40 \mathrm{kN} / \mathrm{m}$ (for the control) to $53 \mathrm{kN} / \mathrm{m}$ (for the composite at CA loading of $0.7 \mathrm{pphp}$ ) with an increase of $28 \%$. Increasing CA loading beyond $0.7 \mathrm{pphp}$, shows a decrease in tear strength. Tear strength variation also confirms the formation of a good adhesion between the phases at a CA loading of $0.7 \mathrm{pphp}$.

\section{Chemical characteristics of NR/LDPE composites}

Figure 4 shows the variation of degree of swelling with CA loading. Degree of swelling decreases with CA loading up to $0.7 \mathrm{pphp}$ and gradually increases after that with the increase in CA loading. The lowest swelling at $0.7 \mathrm{pphp}$ CA loading is associated with the maximum level of interactions developed between NR and LDPE. Swelling property of a thermoplastic elastomer defines the solvent absorption capacity of that material. If the material exhibits a high degree of swelling, it can absorb a high amount of solvent without completely dissolving in it. Further, the coupling of the titanate allows elimination of air voids in plastic (Monte, 2005). Titanate-treated inorganic fillers are organophilic and absorb more organic solvent ( $\mathrm{p}$-xylene) at higher CA loadings.

Gel content is also used for determining the solvent resistance of a thermoplastic or rubber. It is known to be directly proportional to the crosslink density. Higher gel content indicates a higher crosslink density and results in a lower degree of swelling. In Figure 4, gel content gradually increases with CA loading up to $0.7 \mathrm{pphp}$ and slightly decreases thereafter with increase in CA loading. The high gel content at $0.7 \mathrm{pphp}$ reconfirms the formation of crosslinks or interfacial interactions in the composite. In addition, formation of gel is associated with ionic linkage of phosphate group. 
Hardness of gel of the composites varied from 32 to 45 IRHD (Figure 4), and is lower than the hardness of the composites. This suggests that the gel contains interacted or cross-linked rubber molecules. The composite at CA

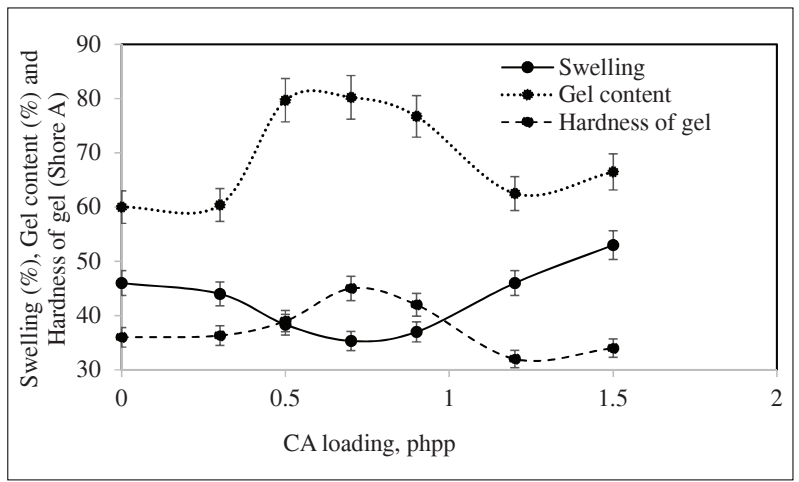

Figure 4: Variation of degree of swelling, gel content and hardness of gel of NR/LDPE composites with CA loading

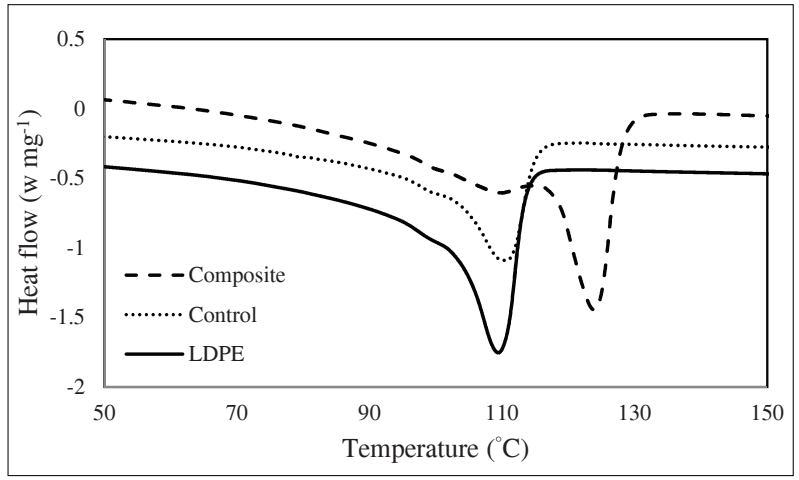

Figure 5: DSC curves of LDPE and gels of the control and the composite at CA loading of $0.7 \mathrm{pphp}$

loading of $0.7 \mathrm{pphp}$ shows the highest hardness of gel due to the presence of more interacted/cross-linked NR. DSC curves of LDPE, gels of the control and the composite at CA loading of 0.7 pphp are given in Figure 5. The gel of the composite at CA loading of $0.7 \mathrm{pphp}$ shows a peak of melting endotherm at $124^{\circ} \mathrm{C}$, while both LDPE and gel of the control show peaks of melting endotherms at $109^{\circ} \mathrm{C}$, revealing the presence of LDPE in gels attached to NR. Shift of peak at melting endotherm of the composite with $\mathrm{CA}$ to a higher temperature indicates the formation of chemical crosslinks between NR and LDPE. Further, gels of the composites with CA show greater ash content compared to the control (Table 4) revealing the presence of more $\mathrm{CaCO}_{3}$ in the gels of the composites containing CA. This suggests the formation of crosslinks between $\mathrm{NR}$ and LDPE through $\mathrm{CaCO}_{3}$.
Water absorption of the composites is shown in Figure 6. It decreases with CA loading up to $0.7 \mathrm{pphp}$ and gradually increases with CA loading. Water, being an inorganic substance is not compatible with organophilic titanate and hence titanate restricts the absorption of water. However, the composite at CA loading of $1.5 \mathrm{pphp}$ showed higher water absorption and it may be due to the presence of excess $\mathrm{CA}$, which makes a weak interface between $\mathrm{CaCO}_{3}$ and polymer (Pocius, 2012). High porosity created at higher CA loadings absorbs higher degree of water. When titanates are incorporated into polymer systems they often promote adhesion, dispersion and improve impact strength (Monte, 1987). Good interfacial adhesions and good $\mathrm{CaCO}_{3}$ dispersion developed in the composite at a CA loading of $0.7 \mathrm{pphp}$ inhibited porosity creation and hence showed lowest water absorption.

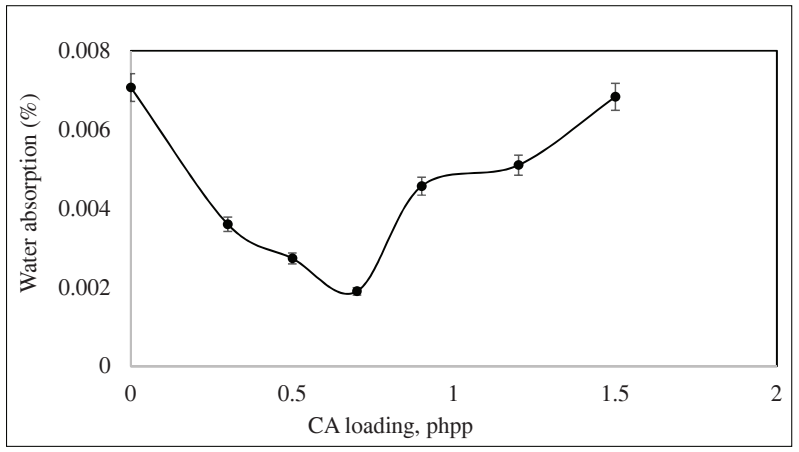

Figure 6: Variation of water absorption of NR/LDPE composites with CA loading

\section{Ageing properties of NR/LDPE composites}

Table 5 shows the ageing properties of the control, and the composites at different CA loadings. Most of the composites showed good retention of tensile properties after ageing and are closer to $90 \%$. Composites at CA loadings of $0.7 \mathrm{pphp}$ and $0.9 \mathrm{pphp}$ showed the highest percentage and hence showed higher resistance to thermal degradation, while that of $1.5 \mathrm{pphp}$ showed poor resistance to thermal degradation. Reactivity function of a titanate coupling agent is very high as it has six reactivity sites. This tetravalent titanium is reacted strongly with filler and polymer and hence, $\mathrm{CA}$ at its optimum loading will react effectively with $\mathrm{CaCO}_{3}$ and NR and LDPE.

\section{Thermal properties of NR/LDPE composites}

Table 3 shows the glass transition temperature $\left(\mathrm{T}_{\mathrm{g}}\right)$, melting temperature $\left(\mathrm{T}_{\mathrm{m}}\right)$ and degree of crystallinity $\left(\mathrm{X}_{\mathrm{c}}\right)$ of the control and the composites at different CA loadings. $\mathrm{T}_{\mathrm{g}}$ decreases with the addition of $\mathrm{CA}$ and 
Table 5: Ageing properties of NR/LDPE composites

\begin{tabular}{lcc}
\hline CA loading, pphp & $\begin{array}{c}\text { Retention of } \\
\text { tensile } \\
\text { strength }(\%)\end{array}$ & $\begin{array}{c}\text { Retention of } \\
\text { elongation at } \\
\text { break (\%) }\end{array}$ \\
\hline Control & 94 & 99 \\
0.3 & 83 & 93 \\
0.5 & 89 & 88 \\
0.7 & 100 & 99 \\
0.9 & 100 & 100 \\
1.2 & 97 & 81 \\
1.5 & 65 & 77 \\
\hline
\end{tabular}

remains unchanged with the $\mathrm{CA}$ loading. Moreover, $\mathrm{T}_{\mathrm{g}}$ measurement revealed the plasticising effect caused by titanate CA loading, which has imparted changes in morphological character (Figure 7). Plasticiser in a polymer lowers the $\mathrm{T}_{\mathrm{g}}$ of the polymer and consequently promotes a change in properties from hard and brittle to those of soft, flexible and tough (Billmeyer, 1984). $\mathrm{T}_{\mathrm{m}}$ variation is not significant up to $0.7 \mathrm{pphp}$, but thereafter at higher loadings $T_{m}$ decreases. $X_{c}$ increases with increase in CA loading up to 0.7 pphp and then decreases, suggesting an effect of CA on crystallinity. $\mathrm{X}_{c}$ of neat LDPE is in the range 50-60\% (Seymour \& Carraher, 1984). It was reported in a previous study (Bajaj et al., 1989 ) that the degree of crystallinity was highest at $0.7 \%$ out of the four concentrations of titanates, $0.3,0.5,0.7$ and $1 \%$ in $\mathrm{PP} / \mathrm{mica}$ composites and it was the optimum loading to create effective interfacial interactions. It was reported in another study (Govorčin et al., 2014) that interfacial adhesion and degree of crystallinity would be increased due to proper filler dispersion in the talc-filled thermoplastic polyurethane/polypropylene blend.

\section{Dynamic mechanical analysis of the NR/LDPE composites}

Figure 8 shows storage modulus, loss modulus and tan $\delta$ versus temperature plots of the simple blend, the control and the composite at CA loading of $0.7 \mathrm{pphp}$. Storage modulus is a measure of the maximum energy stored in the material during one cycle of oscillation and it provides valuable insight into the stiffness of the composites, representing the elastic nature of material. As temperature increases, the components become more mobile and lose their close packing arrangement and hence the storage modulus is decreased at the glass transition region. In the rubbery region, change in storage modulus is insignificant (Pipattananukul et al., 2014). Due to the development of interfacial adhesions, the composite at a CA loading
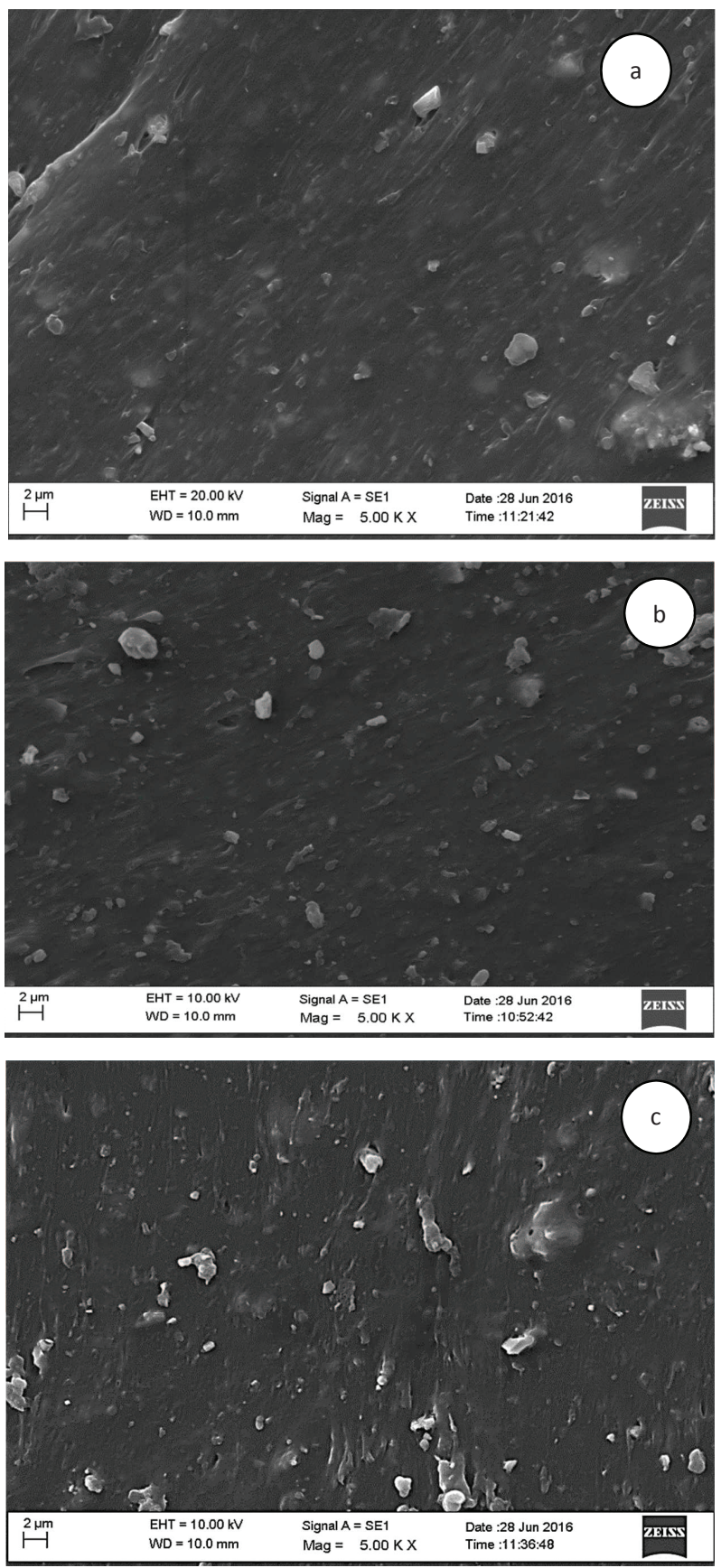

Figure 7: SEM images of tensile fracture surfaces of (a) the control; (b) composite at CA loading of 0.7 pphp and (c) composite at CA loading of $1.2 \mathrm{pphp}$

of 0.7 pphp showed the highest storage modulus. Loss modulus is a measure of energy dissipated heat due to friction and internal motion, representing the viscous behaviour. Greater heat dissipation was found with the control and the composite compared to the simple blend 
due to the presence of $\mathrm{CaCO}_{3}$. $\mathrm{CaCO}_{3}$ may act as a barrier to the mobility of LDPE chains. Tan $\delta$ is the ratio of loss modulus to storage modulus and is called the damping factor. The temperature at $\tan \delta$ peak is taken as $T_{g}$ of a material and it indicates the compatibility of phases in a composite. However, interfacial adhesions generated in the composite may not be significant enough to change the $\mathrm{T}_{\mathrm{g}}$ observed under DMA.

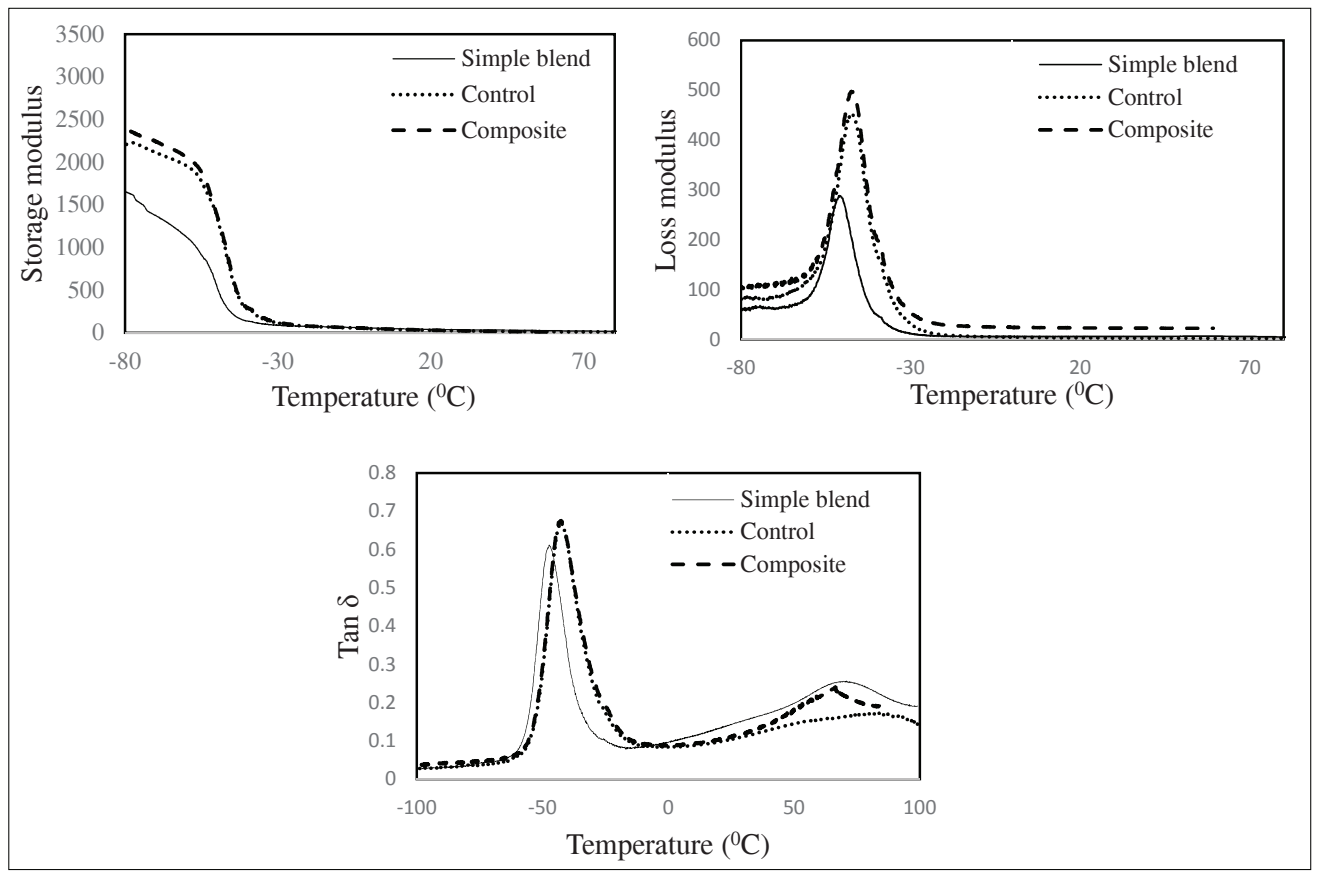

Figure 8: Storage modulus, loss modulus and $\tan \delta$ of NR/LDPE composites of the simple blend, the control and the composite at CA loading of $0.7 \mathrm{pphp}$

\section{Morphological analysis of NR/LDPE composites}

Figure 7a shows the SEM image of fracture surfaces of the control, while Figure $7 \mathrm{~b}$ and Figure $7 \mathrm{c}$ show those of the composites at CA loadings of 0.7 and 1.2 pphp, respectively. These images clearly show that LDPE is dispersed in the NR matrix. The control and the composite exhibit smooth fracture surfaces and good interfacial adhesions between the NR and LDPE phases. Figure $7 \mathrm{c}$ shows a rough surface with a clear phase separation due to poor interfacial adhesions between phases. This phase separation confirms the inferior mechanical properties obtained at higher CA loadings. Figure $7 \mathrm{~b}$ shows a homogeneous dispersion of $\mathrm{CaCO}_{3}$ in the NR/LDPE composite. This indicates the efficiency of mixing, which was attributed to a good interfacial interaction between NR/LDPE and $\mathrm{CaCO}_{3}$. Interfacial bonding is also improved due to the trans-esterification reaction of CA. Further, as in Figure 7c, the NR phase is deformed and curled and hence fracture surface features a typical elastic failure (Sukhanova et al., 1999).
Furthermore, the composite which was prepared with CA loading of 1.2 pphp showed weak interfaces. Moreover, the morphological analysis shows that the best interfacial adhesion between NR and LDPE phases is at a CA loading of $0.7 \mathrm{pphp}$.

\section{CONCLUSION}

Hardness of the composites in the range of 61-67 IRHD and the rubbery character on the stress-strain curves reveal the presence of NR as the continuous phase in the composites. Tensile strength, elongation at break and tear strength of the composites increased with incorporation of CA, further increased with CA loading up to $0.7 \mathrm{pphp}$ and then decreased. This property enhancement proposes that $\mathrm{CA}$ at lower loadings could develop interfacial adhesions and/or good dispersion of $\mathrm{CaCO}_{3}$ within the composites. The higher gel content and the lower degree of swelling of the composites at CA loading between 0.5 to $0.9 \mathrm{pphp}$ indicate the presence of higher interfacial adhesions in the respective composites. Melting 
endotherm appeared in the DCS curve, lower hardness values, and higher ash contents showed for the gels of the composites confirm the presence of LDPE, NR and $\mathrm{CaCO}_{3}$ in the crosslinking structure. Further, the shift of melting endotherm to a higher temperature for the gel of composite at CA loading of $0.7 \mathrm{pphp}$ reconfirms the formation of greater extent of adhesions between LDPE and $\mathrm{NR}$ through $\mathrm{CaCO}_{3}$. The lowest water absorption, the highest degree of crystallinity of LDPE phase, the highest storage and loss modulus shown for the composite at CA loading of 0.7 pphp explains that the composite, compared to the control and the composites at other CA loadings, has the greatest compatibility between NR and LDPE phases. Retention of tensile properties after thermal ageing was excellent. Smooth fracture surface observed in the SEM image of the composite at CA loading of $0.7 \mathrm{pphp}$ reconfirms the presence of good interfacial adhesions and proper dispersion of $\mathrm{CaCO}_{3}$ in the NR/LDPE blend. Therefore, the optimum CA loading for the 70/30 NR/LDPE composite is identified as 0.7 pphp.

\section{Acknowledgement}

The authors wish to thank the Rubber Research Institute of Sri Lanka, Samsons Compounds (Pvt.) Ltd., Pheonix Industries, and Lanka Minerals and Chemicals (Pvt.) Ltd., for supplying raw materials for the study.

\section{REFERENCES}

Alkadasi N.A., Kapadi U.R. \& Hundiwale D.G. (2004). Effect of titanate coupling agent on the mechanical properties of clay-filled polybutadiene rubber. Journal of Applied Polymer Science 93(3): 1299-1304.

DOI: https://doi.org/10.1002/app.20549

Alkadasi N.A., Hundiwale D.G. \& Kapadi U.R. (2006). Effect of titanate coupling agent on the mechanical properties of flyash filled chloroprene rubber. Polymer Plastics Technology and Engineering 45(3): 415-420. DOI: https://doi.org/10.1080/03602550600553887

Bajaj P., Jha N.K. \& Jha R.K. (1989). Effect of titanate coupling agents on mechanical properties of mica-filled polypropylene. Polymer Engineering and Science 29(8): 557-563.

DOI: https://doi.org/10.1002/pen.760290810

Baker A.M.M. \& Mead J. (2000). Thermoplastics. In: Modern Plastics Handbook (ed. C.A. Harper). McGrow Hill, USA.

Bengtsson M., Gatenholm P. \& Oksman K. (2005). The effect of crosslinking on the properties of polyethylene/wood flour composites. Composites Science and Technology 65(10): 1468-1479.

DOI: https://doi.org/10.1016/j.compscitech.2004.12.050
Betingytė V., Žukienė K., Jankauskaitė V., Milašienė D., Mickus K.V. \& Gulbinienè A. (2012). Influence of calcium carbonate fillers on the properties of recycled poly (e-caprolactone) based thermoplastic polyurethane. Materials Science 18(3): 243-249.

Bhowmick A.K. \& White J.R. (2002). Thermal, UV-and sunlight ageing of thermoplastic elastomeric natural rubber-polyethylene blends. Journal of Materials Science 37(23): 5141-5151.

DOI: https://doi.org/10.1023/A:1021076724403

Billmeyer F.W. (1984). Textbook of Polymer Science, pp. 339. John Wiley and Sons, New York, USA.

Bosshard A.W. \& Schlumpf H.P. (1987). Fillers and Reinforcements in Plastics Additives (eds. R. Gachter \& H. Muller), pp. 407-420. Hanser Publishers, New York, USA.

Croitoru C., Pascu A., Roata I.C. \& Stanciu E.M. (2017). Obtaining and characterization of polyolefin-filled calcium carbonate composites modified with stearic acid. IOP Conference Series: Materials Science and Engineering 209(1): Article ID 012041.

DOI: https://doi.org/10.1088/1757-899X/209/1/012041

Doufnoune R., Haddaoui N. \& Riahi F. (2008). Effects of coupling agents on the tensile properties of calcium carbonate filled LDPE compatibilized with maleic anhydride-g-LDPE (Part I). International Journal of Polymeric Materials 57(4): 295-318.

DOI: https://doi.org/10.1080/00914030701476998

George S., Joseph R., Thomas S. \& Varghese K.T. (1995). Blends of isotactic polypropylene and nitrile rubber: morphology, mechanical properties and compatibilization. Polymer 36(23): 4405-4416.

Govorčin Bajsić E., Rek V. \& Ćosić I. (2014). Preparation and characterization of talc filled thermoplastic polyurethane/ polypropylene blends. Journal of Polymers 2014: Article ID 289283.

DOI: http://dx.doi.org/10.1155/2014/289283

Hernández-Sánchez F., Olayo R. \& Manzur A. (1999). Effect of NR and EPDM on the rheology of HDPE/PP blends. Polymer Bulletin 42(4): 481-488. DOI: https://doi.org/10.1007/s002890050492

Kattas L., Gastrock F., Levin I. \& Cacciatore A. (2000). Plastic additives. In: Modern Plastics Handbook (ed. C.A. Harper). McGraw-Hill, USA.

Mahapram S. \& Poompradub S. (2011). Preparation of natural rubber (NR) latex/low density polyethylene (LDPE) blown film and its properties. Polymer Testing 30(7): 716-725. DOI: https://doi.org/10.1016/j.polymertesting.2011.06.006

Maziad N.A., El-Nashar D.E. \& Sadek E.M. (2009). The effects of a silane coupling agent on properties of rice husk-filled maleic acid anhydride compatibilized natural rubber/lowdensity polyethylene blend. Journal of Materials Science 44(10): 2665-2673.

DOI: https://doi.org/10.1007/s10853-009-3349-3

Mohammed A. \& Qusay K. (2014). The study of the development of natural rubber blends using different types 
of polymers and fillers on the mechanical and chemical properties of the vulcanizates. Journal of Natural Sciences Research 4 (24): 60-73.

Monte S.J. \& Sugerman G. (1987). Ken-React Reference Manual: Titanate, Zirconate And Aluminate Coupling Agents. Kenrich Petrochemicals, Bayonne, USA.

Monte S.J. (2005). Titanate coupling agents. Functional Fillers for Plastics, pp. 85-104. John Wiley and Sons, New York, USA.

DOI: https://doi.org/10.1002/3527605096.ch5

Muzzy J.D. (2009). Thermoplastics Properties, $1^{\text {st }}$ edition, chapter 3. Georgia Institute of Technology, Atlanta, USA.

Nabil A.N.A., Abdullah M.A.A. \& Zhengping F. (2016). Study on the effect of titanium (IV) oxide as coupling agent on the mechanical properties of magnesium hydroxide filled HDPE/EVA composites. Chemistry Research Journal 1(5): 19-25.

Pietrasanta Y., Robin J.J., Torres N. \& Boutevin B. (1998). Mechanical performance improvement of low-density polyethylene blends. Mechanics of Time-Dependent Materials 2(1): 85-95.

DOI: https://doi.org/10.1023/A:1009756818443

Pipattananukul N., Ariyawiriyanan W. \& Kawahara S. (2014). Thermal behavior of vulcanized deproteinized natural rubber nano-composites. Energy Procedia 56: 634-640. DOI: https://doi.org/10.1016/j.egypro.2014.07.202

Pocius A.V. (2012). Adhesion and Adhesives Technology: An Introduction. Carl Hanser Verlag GmbH Co., Munich, Germany.

DOI: https://doi.org/10.3139/9783446431775
Rubin I.I. (ed.) (1990). Handbook of Plastic Materials and Technology, pp. 1745. John Wiley and Sons, New York, USA.

Saci H., Bouhelal S., Bouzarafa B., López D. \& FernándezGarcía M. (2016). Reversible crosslinked low density polyethylenes: structure and thermal properties. Journal of Polymer Research 23(4): 1-9. DOI: https://doi.org/10.1007/s10965-016-0965-x

Sampath W.D.M., Edirisinghe D.G. \& Egodage S.M. (2015). Improvement of physico-mechanical properties of calcium carbonate filled natural nubber and low density polyethylene blends with titanate coupling agent. Moratuwa Engineering Research Conference (MERCon), pp. 228-233. DOI: https://doi.org/10.1109/MERCon.2015.7112350

Seymour R.B. \& Carraher Jr C.E. (1984). Thermal properties of polymers. In: Structure-Property Relationships in Polymers, pp. 83-93. Springer, USA.

Srilathakutty R., Joseph R. \& George K.E. (1999). Studies on microcellular soles based on natural rubber/polyethylene blends. Journal of Materials Science 34(7): 1493-1495.

Sukhanova T.E., Baklagina Y.G., Kudryavtsev V.V., Maricheva T.A. \& Lednický F. (1999). Morphology, deformation and failure behaviour of homo-and copolyimide fibres: 1 . Fibres from 4, 4'-oxybis (phthalic anhydride)(DPhO) and p-phenylenediamine (PPh) or/and 2, 5-bis (4-aminophenyl)pyrimidine (2, 5PRM). Polymer 40(23): 6265-6276.

Wickramaarachchi W.V.W.H., Walpalage S. \& Egodage S.M. (2016). Identification of the polyethylene grade most suitable for natural rubber-polyethylene blends used for roofing applications. Engineer: Journal of the Institution of Engineers, Sri Lanka 49(4): 9-14.

DOI: https://doi.org/10.1023/A:1004595625712 